\title{
AMEBAS DE VIDA LIVRE NO INTESTINO HUMANO EVIDÊNCIAS DE PARASITISMO
}

\author{
Hércules de Moura (1), Homero Coutinho SALAzar (2), Octavio FERNandes (3), Denise Costa
} LISBOA (4) e Francisca Gonçalves de CARVALHO (5)

\section{R E S U IM O}

Foram cultivadas fezes de 620 indivíduos para a pesquisa de amebas de vida livre, sendo 514 pacientes do Hospital Universitário Pedro Ernesto (UERJ) e 106 crianças e adultos de um orfanato. Foram positivas 70 amostras $(11,2 \%)$ sendo 55 provenientes de pacientes do HU-UERJ e 15 de internos do orfanato. Foram isoladas 60 amostras de Acanthamoeba, 6 de Vahlkampfia, 5 de Hartmannella e 1 Echinamoeba. Alguns individuos tiveram cultura de fezes repetidamente positiva para Acanthamoeba durante dois meses de observação. Das amostras de Acanthamoeba isoladas, 28 foram inoculadas em camundongos por via intranasal, tendo sido reisoladas $16(57.1 \%)$ amostras à partir de cérebro e (ou) pulmões dos animais. O estudo histopatológico demonstrou processo inflamatório agudo com presença de polimorfonucleares e amebas no cérebro e pulmões de alguns animais. O encontro de amostras patogênicas em fezes humanas reforça a hipótese do eventual desenvolvimento, em indivíduos portadores, de meningoencefalite amebiana granulomatosa, como infecção oportunística de origem endógena.

\section{N T R O D U G $\mathbf{A} O$}

A hipótese de que as amebas de vida livre (AVL) fossem agentes de infecção para o homem e animais foi primeiramente aventada por CULBERTSON \& col. 4 ,5. Posteriormente FOWLER \& CARTER ${ }^{7}$ e BUTT ${ }^{1}$ descreveram os primeiros casos de Meningoencefalite Amebiana Primária (MEAP).

Hoje sabemos que as amebas dos gêneros Naegleria e Acanthamoeba são agentes infecciosos para o homem, a primeira causando meningoencefalite aguda e quase sempre fatal, e a segunda quadros diversos, como pneumonias, dermatites, úlceras de córnea, além de menin. goencefalite granulomatosa (MEG) ${ }^{12}$.
Tais protozoários são comumente encontrados em diversos tipos de coleções de água em todo o mundo, e, no Brasil, têm sido isoladas a partir de água mineral, de chafarizes, lagos, piscinas e da rêde de distribuição urbana do Rio de Janeiro 10,16,19.

A determinação da patogenicidade de amostras de AVL, isoladas a partir de material biológico ou de ambiente, é assunto controverso devido aos diferentes critérios adotados 2,6,13, mas, após instilação nasal em camundongos, o acesso dos protozoários ao sistema nervoso central ocorre através do nervo olfativo ou ain-

Trabalho realizado na Disciplina de Parasitologia, Departamento de Patologia e Laboratórios da Faculdade de Ciências Médicas - Universidade do Estado do Rio de Janeiro. Financiado em parte pela FINEP - Processo n.o $4382 / 0270-00$

(1) Professor Auxiliar - Disciplina de Parasitologia. Faculdade de Ciências Médicas - UERr, Brasil

(2) Professor Adjunto - Responsável pela Disciplina de Parasitologia - Faculdade de Ciências Médicas - UERJ

(3) Acadêmico de Medicina - Estagiário - Disciplina de Parasitologia - Faculđade de Ciências Médicas - UERJ

(4) Bióloga - Estagiária - Disciplina de Parasitologia - Faculdade de Ciências Médicas - UERJ

(5) Médica - Hospital dos Servidores do Estado (INAMPS) e Hospital do IASERJ 
MOURA, H. de; SALAZAR, H. C.; FERNANDES, O.; LISBOA, D. C. \& CARVALHO, F. G. de - Amebas de vida livre no intestino humano. Evidências de paràsitismo. Rev. Inst. Med. trop. São Paulo 27:150-156, 1985.

da por disseminação hematogênica a partir de foco pneumônico 13

O encontro das amebas de vida livre em fezes humanas vem sendo assinalado desde o início do século ${ }^{18}$, mas desde que SCHAUDDrNN estabeleceu que a única ameba patogênica para o homem seria Entamoeba histolytica, tais achados foram interpretados como casos de pseudoparasitismo.

O objetivo do presente trabalho é relatar o ısolamento de AVL a partir de fezes de dois grupos estudados no Rio de Janeiro, assinalar a eliminação intermitente dos protozoários por alguns indivíduos acompanhados durante dois meses após o primeiro isolamento, bem como relatar os estudos feitos, com algumas amostras isoladas, para a demonstração da patogenicidade para animais de laboratório.

\section{MATERLAL E MÉtodos}

Foram cultivadas fezes de 514 pacientes do Hospital Universitário Pedro Ernesto (UERJ), sendo a amostragem feita por sorteio à partir de material recebido para diagnóstico. Os outros individuos pesquisados eram internos e funcionários de um orfanato localizado na zona norte do Rio de Janeiro, em que foram colhidas as fezes de 86 crianças e de 20 adultos. Os individuos positivos do orfanato tiveram suas fezes cultivadas por mais três vezes, a cada 15 dias. Cerca de $2 \mathrm{~g}$ de fezes foram diluidas em água destilada esterilizada e colocadas em placas de Petri contendo ágar não nutriente e recobertas com tapetes de suspensão de Aerobac. ter aerogenes morto pelo calor (ANNA). As placas foram incubadas às temperaturas de $37^{\circ} \mathrm{C}, 40^{\circ} \mathrm{C}$ e $45^{\circ} \mathrm{C}$ e no $5^{\circ}$ e $100^{\circ}$ dias foram invertidas e observadas em microscópio comum. Para o isolamento e identificação das amostras foi utilizada a metodologia de MOLET \& KREIMER ${ }^{15}$, PAGE ${ }^{17}$ e MOURA ${ }^{16}$.

Foram realizados testes de patogenicidade com algumas amostras de Acanthamoeba isoladas. Cada uma das amostras testadas, após crescimento em meio ANNA, durante 24 a 36 horas a $37^{\circ} \mathrm{C}$, foi recolhida e concentrada por centrifugação a $1500 \mathrm{rpm}$ durante 10 minutos, tendo sido a concentração final de suspensão ajustada entre $10^{4}$ e $10^{6}$ trofozoítos por mililitro.
Foram utilizados camundongos albinos "outbred" pesando entre 10 e 15 gramas. Os animais, em grupos de 5, foram inoculados por via intranasal com 0,02 a $0,04 \mathrm{ml}$ de suspensão de amebas e observados por 30 dias. Após a morte ou sacrifício dos animais, fragmento de cérebro e pulmões foram retirados e colocados em placas com ANNA, incubados a $37^{\circ} \mathrm{C}$ e observados até o $10 .^{\circ}$ dia.

Para estudo anátomo-patológico os órgãos foram fixados em PBS - formol a 10\%, incluícos em parafina, clivados e corados com Hematoxilina-Eosina.

\section{RESULTADOS}

Na Tabela I observamos que $10 \%$ das fezes provenientes de pacientes do HU.UERJ foram positivas para amebas de vida livre dos gêneros Acanthamoeba, Echinamoeba e Vahlkampfia e que $52 \%$ das amostras de Acanthamoeba, quando inoculadas em camundongos, foram reisoladas de seus órgãos, enquanto que $14 \%$ dos individuos do orfanato tiveram suas fezes positivas para Acanthamoeba, Hartmannella e Vahl. kampfia.

Quanto as amostras provenientes dos indivíduos do orfanato foram cultivadas outras três vezes foi observado o isolamento de Acanthamoeba (Figs. 1 e 2) na segunda amostra de dois indivíduos. Seis individuos, inclusive aqueles positivos na segunda amostra, apresentaram positividade na terceira, enquanto que na quarta amostra apenas dois continuaram eliminando o protozoário.

Apesar de não ter sido proposto neste estudo, em nenhum momento foram observados, nos indivíduos estudados, episódios sugestivos de doença intestinal por estes protozoários.

Na Tabela II estão relacionadas as amostras de Acanthamoeba inoculadas em camundongos, o tempo de sobrevivencia dos animais após a inoculação e os órgãos de onde os protozoários foram reisolados. Das 19 amostras isoladas de fezes de pacientes do HU-UERJ, quatro foram reisoladas somente a partir dos pulmões, uma somente a partir de cérebro e cinco foram reisoladas de cérebro e pulmões. A sobrevivência dos animais foi bastante variada, sendo que a amostra F 401 causou a morte de todos ainda na primeira semana após a inoculação. 
Moura, H. de; Salazar, H. C. Ferkandes, O. LISBOA, D. C. \& Caryal.Ho, P. G. de - amehas de vida livre no intestino humano. Evidèncias de parastismo. Res. Inst. Med. trep. Rase rate 27:150-156, 1965,

$$
\text { TA B E L A } T
$$

Orifum das umostras pesquinadas, ueneros de amebas de vidu livre inoladus e testes de patogenicidude

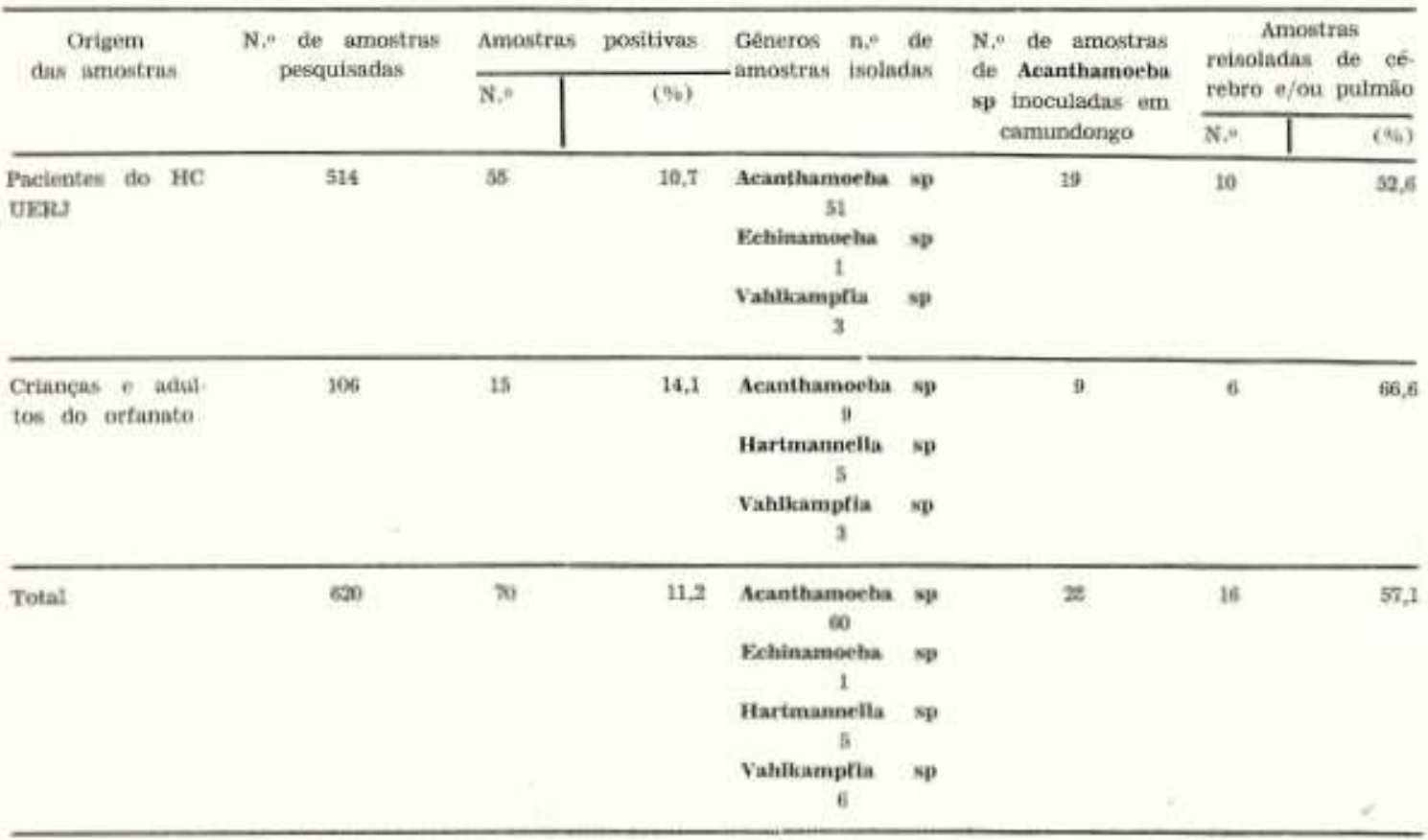

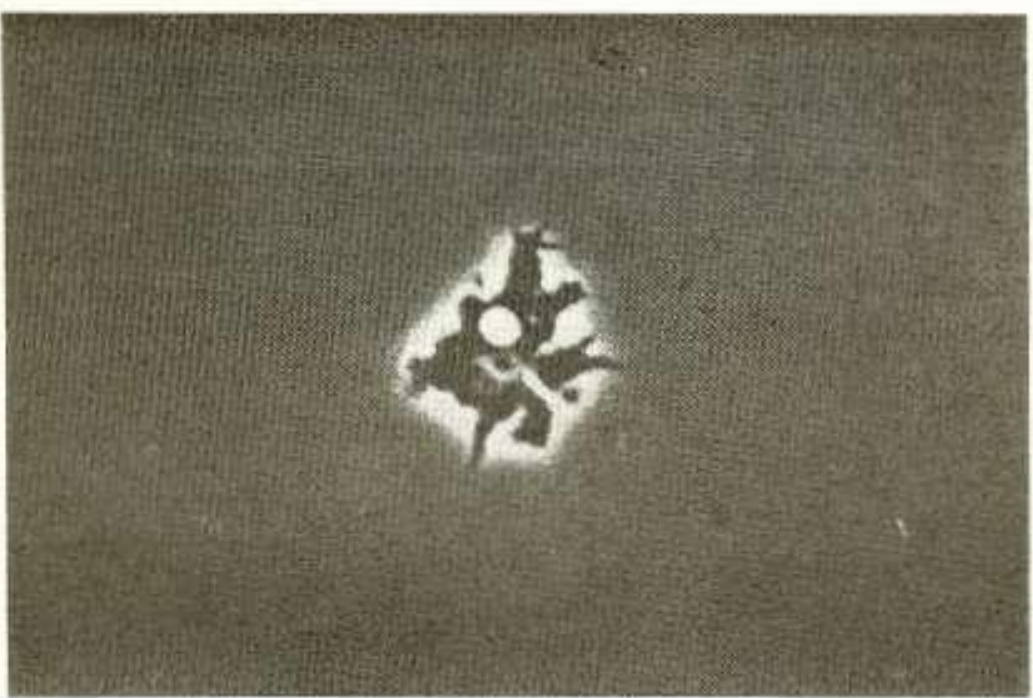

Fig. 1 - Trofosoito de Acantha. moeba sp. Notar bcantopodios contraste de fare. $1000 \times$

Todas as amostras de Acanthamoeba isoladas de individuos do orfanato foram inoculadas e destas, seis foram reisoladas concomitantemente de cérebro e pulmōes e os animais inoculados com quatro delas morreram a partir da primeira semana de infecçầ.

O estudo histopatológico realizado no cêre. bro e pulmôes de alguns animais de cujos ór- gãos houve reisolamento de Acanthamoeba em cultura, demonstrou reaçăo inflamatória comprometendo o parênquima, com presença de infiltrado inflamatório predominantemente de leucócitos polimorfonucleares e amebas. Nas Figs. 3 e 4 observamos cortes de tecido cere. bral e pulmonar de camundongo inoculado com 
MOURA, H. de: SALAZAR, H. C; FERNANDES, O.; LISBOA, D. C. \& CARVALHO, P. G. de - Amebas de vida livre no intestino humano. Evidéncias de parasitistno. Rev. Inst. Med. trop. São Paulo 27:150-156, 1985,

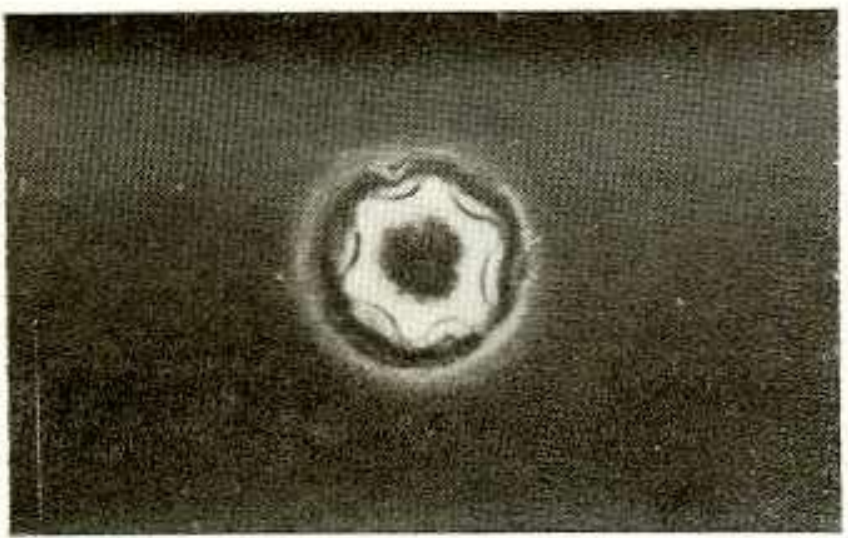

Pig. 2 - Cisto de Acanthamoeba sp (grupo II) - Contraste de fase: $400 \mathrm{X}$

TABELA II

Amostras de Acanthameeba sp inoculadas em camundongo albino, tempo de vicha pós-inoculaçio e reisolameato em cultura Origem das amostras Amostras inoculadas Morte (n.e de dias pós-inóculo) Nio de unimais positivos em Pulmåo Cérebro

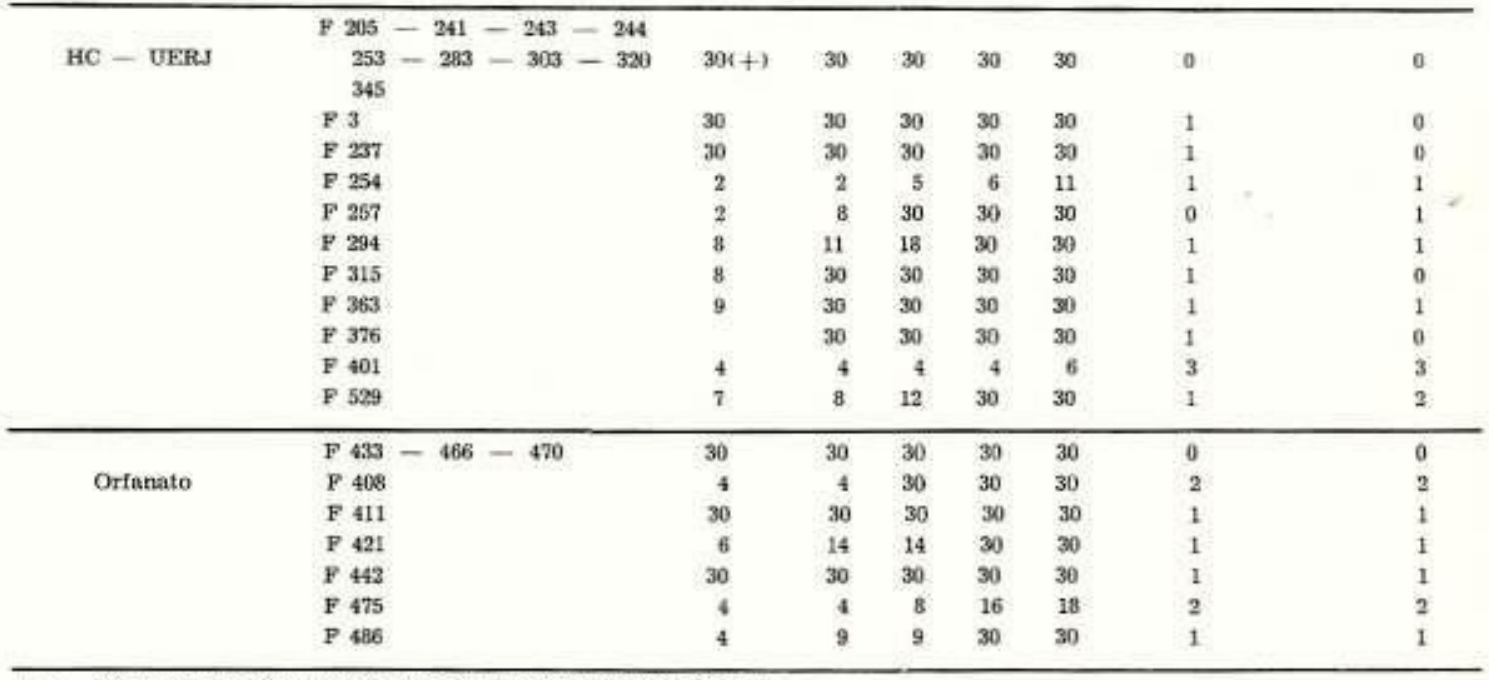

$(+)$ - Todos que sobreviveram ate o $30 . "$ dia foram sacrificados

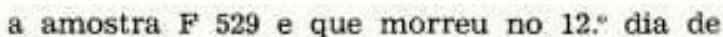
infecçāo.

\section{DISCUSSÃO}

Amebas de vida livre tem sido observadas e isoladas a partir de fezes humanas sendo Acan. thamoeba, Hartmannella, Naegleria e Vahlkampfia os gêneros mais frequentemente isolados 3,8 , $9,14,18$.

Em estudo realizado com estudantes universitários de diversas regiōes da Costa Rica, CHINCHILLA \& col. ${ }^{3}$ relataram positividade para amebas de vida livre de $8,2 \%$ das amostras examinadas. Nos dois grupos que estuda- mos obtivemos $10 \%$ e $14 \%$ de positividade, sendo encontrada maior prevalência na populaçäo de comunidade fechada.

$\mathrm{O}$ encontro destes protozoărios em fezes pode ser interpretado de diferentes maneiras Eles podem ter sido ingeridos acidentalmente, pois estão presentes em águas de abastecimen. to, água mineral e até alimentos $\$, 10.19$ e serem eliminados sob a forma cistica. A colonização do orofaringe ou do tubo digestivo destes indi. viduos, é outra hipótese a ser considerada Nestes casos os protozoários se desencistariam e se multiplicariam naqueles locais $e$, ao che 
MOURA, H. de; SALAZAR, H. C; Fernandes, O.; LISBOA, D. C. A CARVALHO, F. G. de. - Amebas de vida livte no intestino humaso. Evidểncias de parasitismo, Rev. Inst. Med. trop. Săo Paulo 27:150-158, 1985.
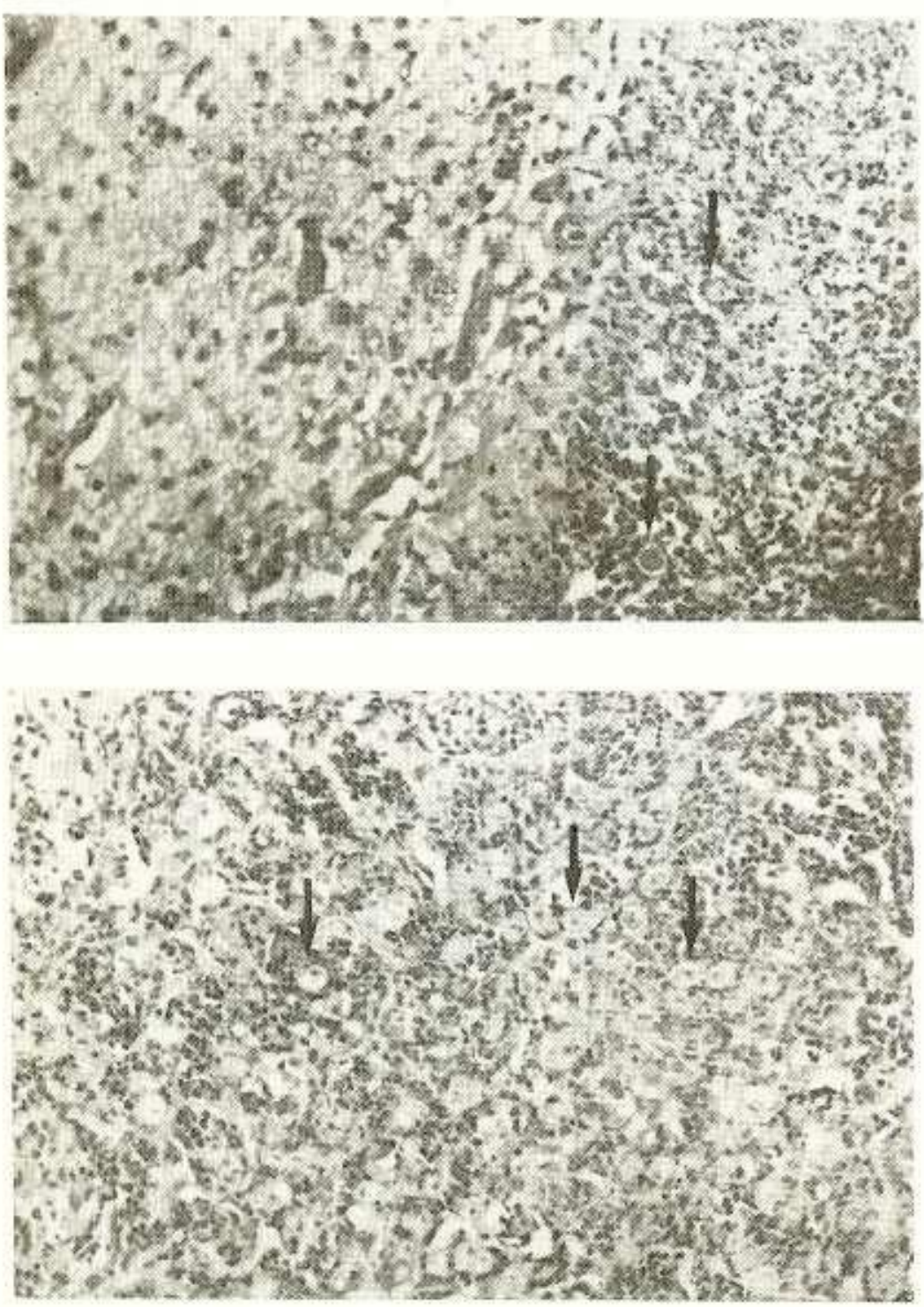

Fig. 3 - Cérebro. Corte histológico mostrando parénguima cerebral reacional (esquerds) e irea de abscesso contendo ce. lulas inflamatórias, material necrótico e trofozoitos de Acan. thamoebai sp (setas)
Fig. 4 - Pulmĩo. Area de abs. cesso contendo material necrotico. eélulas inflamatóriss e numes cosos troforoitos de Acanthamoeha sp (setas) garem ao ambiente, cumpririam parte do seu ciclo biológico.

No presente estudo, os testes de patogenicidade realizados com as amostras de Acan. thamoeba cultivadas a partir de fezes humanas, demonstraram que $57,1^{0} \%$ das mesmas foram reisoladas a partir de cérebro e(ou) pulmōes de camundongos inoculados por via intranasal.

A inoculaçao intranasal de suspensōes de trofozoitos de amebas de vida livre em camun. dongos é sujeita a muitas variáveis 6 , pois é influenciada por fatores do hospedeiro, como a espécie, idade, sexo e, por fatores do parasito, como a virulència da amostra, fase do cres- cimento em cultura e número de amebas no inóculo, Apesar destas limitaçōes, é a via que melhor imita as condiçōes de infecçāo reconhecidas até o momento.

De acordo com este critẻrio, foram consideradas patogénicas as amostras reisoladas a partir dos tecidos dos animais inoculados, o que é expressivo indicador da patogenicidade das mesmas, pois observamos que os animais submetidos a exame histopatológico apresentaram processo broncopneumônico e meningoen. cefalite aguda.

As implicaçôes destes dados do ponto de vis. ta da nosologia humana sắo discutíveis e devem 
MOURA, H. de; SALAzAR, H. C.; FERNANDES, O.; LISBOA, D. C. \& CARVALHO, F. G. de - Amebas de vida livre no intestino humano. Evidências de parasitismo. Rev. Inst. Med. trop. São Paulo 27:150-156, 1985.

ser avaliados com cautela. A hipótese de pseudoparasitismo deve ser considerada, mas não podemos deixar de valorizar o achado de culturas de fezes positivas para Acanthamoeba em alguns indivíduos por duas e até três vezes no intervalo de dois meses.

Tais achados, aliados aos da literatura 8:11, 12,14 nos levam à suposição de que as amebas isoladas sejam, na realidade, habitantes do tubo digestivo com capacidade de, em determinadas condiçōes, invadir os tecidos do hospedeiro, - que encontra respaldo nos resultados dos testes de patogenicidade realizados em camundongos.

$O$ encontro de amebas de vida livre patogênicas em fezes humanas reforça a hipótese de eventual desenvolvimento, em individuos por. tadores, de infecções extra-intestinais de origem endógena, como a meningoencefalite granulomatosa.

\section{SUMMARY}

\section{Free-living amoebae in human bowel: Evidence of parasitism}

Cultures for free-living amoebae were made from feces of 620 individuals of which 514 were patients from the University Hospital Pedro Ernesto (Rio de Janeiro) and, 106 were children and adults of an orphanage.

Positive results were obtained in 70 specimens $(11.2 \%), 55$ from the hospital patients and 15 from the orphanage. 60 Acanthamoeba, 6 Vahlkampfia, 5 Hartmannelia and, 1 Echina. moeba were isolated.

Some individuals were repeatedly positive for Acanthamoeba during the 2 months of observation.

Of the isolated Acanthamoeba, 28 were inoculated intranasally. 16 Strains $(57.1 \%)$ were reisolated from brain and or lungs of the animals. The histopathology revealed an acute in flammatory process with polymorphonuclear neutrophils and amoebae in the brain and lungs of some of the animals.

The isolation of pathogenic strains of Acanthamoeba from human feces supports the hypothesis of eventual development, in carriers, of granulomatous amebic meningoencephalitis as an opportunistic endogenous infection.

\section{REFERENCIAS BIBLIOGRAFICAS}

1. BUTT, C. G. - Primary amoebic meningoencephalitis. New Engl. J. Med. 274: 1473-1476, 1966.

2. CERVA, L. - Studies of limax amoebae in swimming pool. Hydrobiologia 38: 141-161, 1971.

3. CHINCHILLA, M.; CASTRO, E.; ALFARO, M. \& PORTILIA, E. - Amebas de vida livre productoras de meningoencephalitis. Primeiros hellazgos en Costa Rica. Rev. Lat. Amer. Microbiol. 21: 135-142. 1979.

4. CULBERTSON, C. G.; SMTTH, J. \& MINNER, J. Acanthamoeba observation on animal pathogenicity. Science 127: 1506, 1958 .

5. CULBERTSON, C. G.; SMITH, J.; COHEN, H. \& MINNER, J. - Experimental infection of mice and monkeys by Acanthamoeba. Amer. J. Pathol. 35: 185197, 1959.

6. DE JONCKHEERE, J. F. - Growth characteristics, cytophatic effect in cell culture, and virulence in mice of 33 type strains belonging to 19 different Acanthamoeba spp. Appl. Environ. Microbiol. 39: 681-685, 1980 .

7. FOWLER, M. \& CARTER, R. F. - Acute pyogenic meningitis probably due to Acanthamoeba sp. Brit. Med. J. 2: $740-742,1965$.

8. JADIN, J. B. - De la dispersion et du cycle des amibes libres. Ann. Soc. belge. Med. Trop. 54: 371. $385,1974$.

9. JADIN, J. B.; WILLAERT, E. \& COMPERE, F. - De la nécessité du contrôle biologique de eaux potables. Bull. Acad. Nat. Med. 156: 995-999, 1972.

10. LISBOA, D. C.; SALAZAR, H. C.; FERNANDES, O. \& MOURA, H. - Isolamento de amebas de vida livre em água da rede urbana na cidade do Rio de Janeiro. In: Congresso da Federación Latino americana de Parasitólogos. 6..$^{\circ}$ São Paulo, 1983. Resumos. São Paulo, 1983, p. 35 .

11. MARTINEZ, A. J. - Acanthamozbiasis and Immunosupression. J. Neuropath. Exp. Neurol. 41: 548-557, 1982.

12. MARTINEZ, A. J. \& DE JONCKHEERE, J. F. - LeS infections par les amibes libres. Bull. Inst. Pasteur 79: $171-205,1981$

13 MARTINEZ, A. J.; NELSON, E. C. \& DUMA, R. J. - Animal model: Primary Amebic (Naegleria) meningoencephalitis in mice. Amer. J. Path. 73: 545-548, 1973.

14. MEHTA, A. P. \& GUIRGES, S. Y. - Acute amoebic dysentery due to free-living amoebae treated with metronidazole. Amer. J. Trop. Med. Hyg. 82: 134. 146, 1979. 
MOURA, H. de; SALAZAR, H. C.; FERNANDES, O.; LISBOA, D. C. \& CARVALFO, F. G. de - Amebas de vida livre no intestino humano. Evidências de parasitismo. Rev. Inst. Med. trop. São Paulo 27:150-156, 1985.

15. MOLET, B. \& KREMER, M. - Techniques d'etudes et critères morfologiques pour l'identification des amibes libres. Bull. Soc. Sci. Vêt. Comp. 78: 215-223, 1976.

16. MOURA, H. - Amebas de vida livre em piscinas: Isolamento, identificação, potencial patogênico. Rio de Janeiro, 1980. (Dissertação de Mestrado) - Fundação Oswaldo Cruz.

17. PAGE, F. C. - An illustrated hey to freshwater and soil amoeba with notes on cultivation and ecology. Cumbria, Eng. Freshwater Biological Association, 1976, (Scient, publ, 34).
18. PINTO, C. - Sobre uma ameba do gênero VahlKamptia encontrada no homem. Mem. Inst. Oswaldo Gruz 15: 122-126, 1922.

19. SALAZAR, H. C.; MOURA, H. \& RAMOS, R. T. Isolamento de amebas de vida livre a partir de água mineral engarrafada. Rev. Saúde públ. São Paulo 16: 261.267, 1982 .

Recebido para publicação em 22/11/1983 